\title{
Contamination of cheese by polycyclic aromatic hydrocarbons in traditional smoking. Influence of the position in the smokehouse on the contamination level of smoked cheese
}

\author{
M. D. Guillén, ${ }^{1}$ G. Palencia, M. L. Ibargoitia, M. Fresno, and P. Sopelana \\ Tecnología de Alimentos. Facultad de Farmacia. Universidad del País Vasco. Paseo de la Universidad, nº 7, 01006, Vitoria, Spain
}

\begin{abstract}
This paper sets out to determine the polycyclic aromatic hydrocarbon $(\mathrm{PAH})$ contamination degree of a traditionally smoked cheese: Herreño cheese, which comes from one of the Canary Islands. Its PAH profile is thoroughly studied by means of gas chromatographymass spectrometry in SIM mode, and compared with that of an unsmoked cheese. Furthermore, a parameter not previously studied is evaluated, namely the influence of the position of the individual cheeses in the smokehouse on their PAH contamination level. Heavy PAH, among which are included most of the carcinogens, are very scarce and their concentrations low. In fact, benz $[a]$ anthracene, together with chrysene+triphenylene, are the only heavy PAH detected in all of the smoked samples studied. The concentration of benzo $[a]$ pyrene, detected only in 1 of the samples, is below the limit established in Spain for the rind of smoked cheese. In contrast, high concentrations of light PAH have been found, especially of naphthalene and its alkyl derivatives, whose effect on human health is not yet well established. The results derived from the analysis of the $\mathrm{PAH}$ profile suggest the potential usefulness of certain ratios between some pairs of PAH (phenanthrene/anthracene, naphthalene/ acenaphthylene) to provide information on the $\mathrm{PAH}$ contamination source. Furthermore, differences have been found, depending on the position of the cheeses in the smokehouse, those placed in the path followed by the smoke being more contaminated. Therefore, the findings of this study could help in improving the design of smokehouses, to decrease the PAH contamination degree of smoked cheese.
\end{abstract}

Key words: polycyclic aromatic hydrocarbons, smoked Herreño cheese, gas chromatography-mass spectrometry, position in the smokehouse

Received June 25, 2010.

Accepted December 31, 2010.

${ }^{1}$ Corresponding author: mariadolores.guillen@ehu.es

\section{INTRODUCTION}

Traditionally manufactured food products are, in general, much appreciated by consumers. Consequently, great interest exists in characterizing these types of products and standardizing their production process to establish the conditions that best obtain homogeneous and high-quality products. What is more, both producers and consumers are increasingly aware of the need for food safety, especially when it undergoes technological treatments that can result in the formation of contaminating compounds. In particular, smoking, which confers specific sensory properties on food, as well as acting as a preservation treatment, can lead to the contamination of food with polycyclic aromatic hydrocarbons (PAH) if it is not sufficiently controlled (Maga, 1988). Polycyclic aromatic hydrocarbons include compounds with a wide range of molecular weights, which can be divided into light (from naphthalene to benz $[a]$ anthracene) and heavy PAH (from benz $[a]$ anthracene onward). The risk of contamination with PAH has special importance in the case of fatty foods such as cheese, due to the lipophilic nature of these contaminants.

Cheese can be smoked either by using smoke flavorings or by traditional smoking, although the use of smoke flavorings for the smoking of cheese is not allowed in Spain. Traditional smoking involves smoke generation and the random deposit of its components on the cheese surface. This methodology is used not only by artisans but also in certain cheese factories. It is widely known that the PAH contamination degree reached by cheese or any food product in traditional smoking depends on very different factors, such as the temperature, the oxygen content, the vegetable matter used for smoke generation or the composition of the food product (Maga, 1988; Bosset et al., 1998; Pagliuca et al., 2003; Anastasio et al., 2004; Guillén et al., 2007).

Taking as an example of a cheese smoked traditionally in a factory, this paper studies the PAH contamination degree of Herreño cheese. This cheese comes from El Hierro Island, the smallest of the Canary Islands, 
and occupies an important position in the Canary Islands market for smoked soft cheeses; however, hardly any studies exist concerning this product (Fresno et al., 2004). This cheese has been traditionally manufactured with milk from different animals, because flocks on this island contain more than one species. This particular cheese is produced from a mixture of goat, cow, and sheep milk, either pasteurized or raw. It is usually marketed as a fresh or a soft cheese, though the demand for ripened cheeses is bringing about the recovery of ripened Herreño cheese. Herreño cheese can be smoked or unsmoked. The smoking process, which is usually performed 1 or $2 \mathrm{~d}$ after making the cheese (Fresno et al., 2004), uses fig tree wood (Ficus carica) and dry prickly pear (Opuntia ficus indica), common vegetable materials which are typical of the islands and contribute specific characteristics to these cheeses. The chemical composition of these 2 vegetable materials has scarcely been studied (Rodríguez-Garcia et al., 2007).

In this paper, the PAH content of some smoked Herreño cheeses is studied and compared with that of an unsmoked one. This will allow us to know how traditional smoking affects the PAH contamination level of this kind of cheese.

The Scientific Committee on Food (SCF) reviewed the presence and toxicity of $\mathrm{PAH}$ in food and issued an opinion on December 4, 2002 (SCF, 2002). The SCF concluded that benzo $[a]$ pyrene may be used as a marker of occurrence and effect of the carcinogenic PAH in food. Afterward, the Commission asked Member States to monitor $\mathrm{PAH}$ (and, in particular, the 15 priority substances identified by SCF as potentially genotoxic and carcinogenic to humans) in the Commission Recommendation 2005/108/EC (European Commission, 2005a). The European Food Safety Authority (EFSA) collected the data submitted in the framework of this recommendation and issued a report where it was stated that the conclusion made by SCF that benzo $[a]$ pyrene is a good indicator for PAH occurrence could not be demonstrated by the monitoring data from the Member States. This statement was based on the fact that benzo[ $[a]$ pyrene was not detected in about $30 \%$ of the samples where other PAH among the 15 SCF priority ones were detected. Therefore, nowadays, benzo $[a]$ pyrene alone is not considered a suitable indicator for the occurrence and toxicity of genotoxic and carcinogenic PAH. Taking this into account, the study includes most of the PAH that can appear in smoked foods, both light and heavy compounds, together with their alkyl derivatives.

The other objective of the study was to evaluate the influence of position of cheese in the smokehouse on the PAH contamination as there are no studies on this topic.

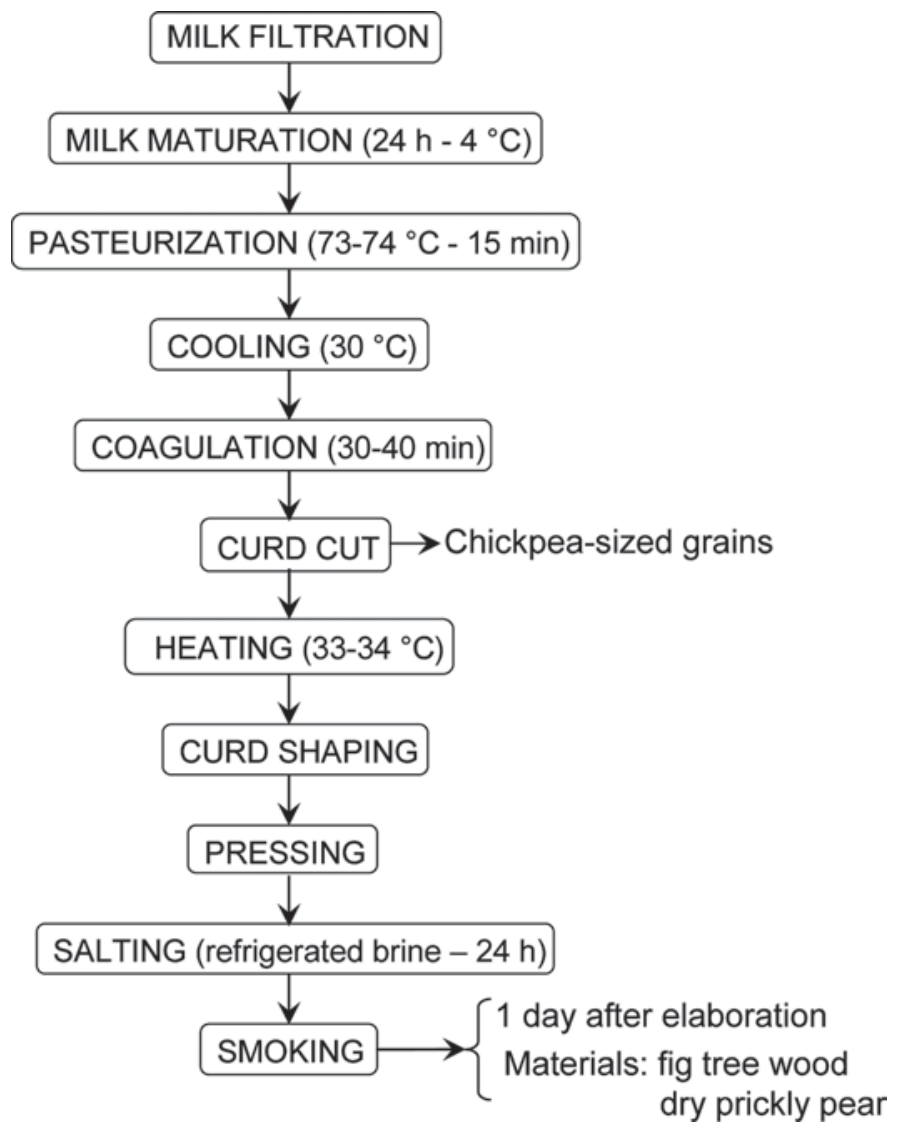

Figure 1. Scheme of the elaboration process of Herreño cheese (Fresno et al., 2004).

\section{MATERIALS AND METHODS}

\section{Samples}

The sample subjects of study were 6 smoked Herreño cheeses, named $1 \mathrm{~A}, 2 \mathrm{~A}, 4 \mathrm{~A}, 1 \mathrm{~B}, 3 \mathrm{~B}$, and $4 \mathrm{~B}$, and another unsmoked one. The weight of the cheeses varied between 2 and $3 \mathrm{~kg}$. A scheme of the elaboration process of Herreño cheese (Fresno et al., 2004) is shown in Figure 1.

Cheeses were placed on metal grilles at 2 different heights (1.20 and $1.80 \mathrm{~m}$ from the floor), both of them above the smoke entry hole. The cheeses placed on the upper part were called $\mathrm{A}$ and those in the lower part B. Both cheeses A and B were assigned numbers from 1 to 4 , according to their distance to the smoke entry. Thus, cheeses with number 1 were the nearest to the smoke entry (approximately $1 \mathrm{~m}$ distance) and those with number 4 the most distant (approximately $5.5 \mathrm{~m}$ ). Considering that smoke tends to go up, it was thought that A cheeses might be more exposed to the smoke action than B; for this reason, and with the aim of obtaining a similar smoking degree, B cheeses were kept 


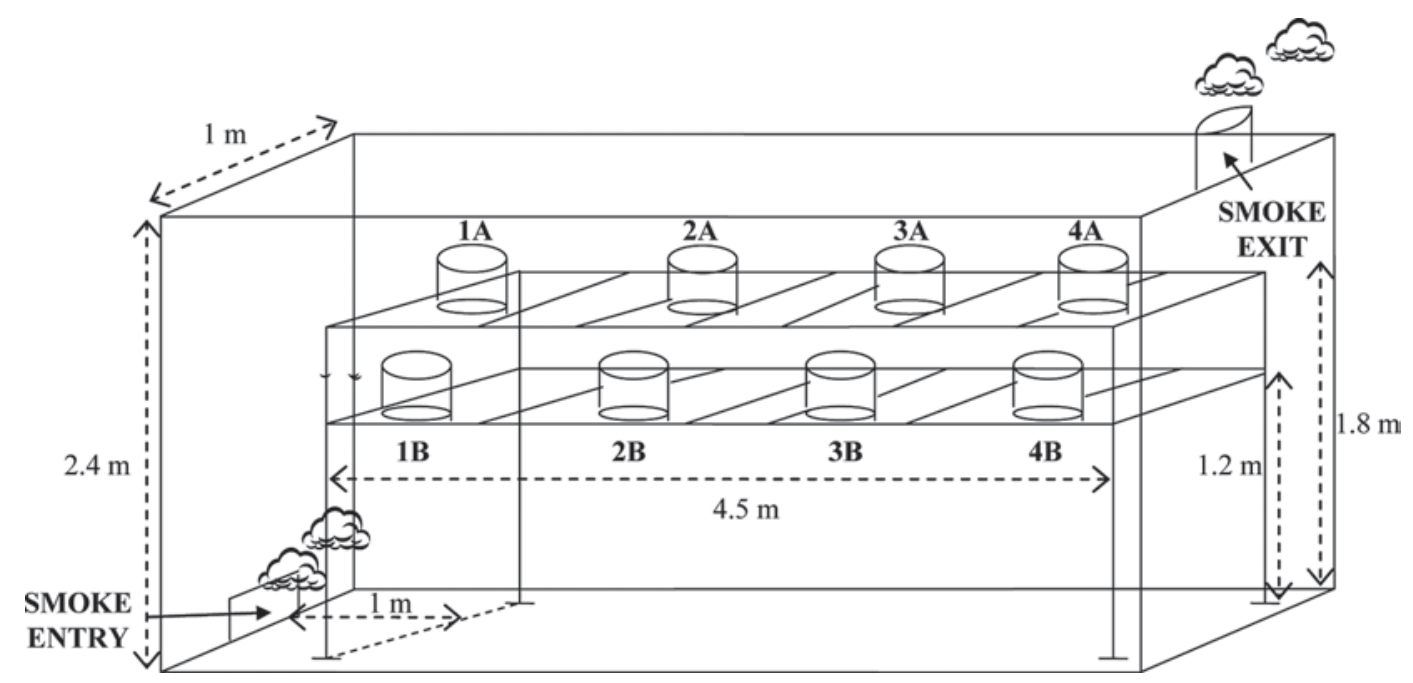

Figure 2. Scheme of the smokehouse for the smoking of the cheeses and position of the cheeses studied. Samples $1 \mathrm{~A}, 2 \mathrm{~A}, 3 \mathrm{~A}$, and $4 \mathrm{~A}$ correspond to the cheeses placed on the upper shelf of the smokehouse and samples $1 \mathrm{~B}, 2 \mathrm{~B}, 3 \mathrm{~B}$, and $4 \mathrm{~B}$ correspond to the cheeses placed on the lower shelf. The numbers refer to the position of the samples: 1: the nearest to the smoke entry; 4 : the most distant from the smoke entry; 2 and 3: intermediate positions.

in the chamber approximately $4 \mathrm{~h}$ and A cheeses only 2 . The situation of the studied cheeses in the smokehouse can be seen in Figure 2.

All of the cheeses were manufactured at the same time, with milk from the same batch, which, as is usual on El Hierro Island, was a mixture of goat, cow, and sheep milk. The manufacturing process was carried out in a local factory, following the traditional methods of production of this type of cheese.

The cheeses were smoked at the same time, in a smokehouse with external smoke generation. The smoke used was produced by the combustion of a mixture of fig tree wood ( F. carica) and dry prickly pear (O. ficus indica) in a combustion chamber next to the smoking chamber. The distance between the smoke source and the smokehouse was approximately $1 \mathrm{~m}$. The smokehouse (see Figure 2) consists of a small-sized room with 2 holes: one for the smoke entry in the lower part of the middle of one wall and another for the smoke exit (chimney) in the ceiling, close to the middle of the opposite wall. During the smoking process, the smoke was continuously being generated and expelled to the atmosphere through the chimney.

The temperature of the smoke was $47^{\circ} \mathrm{C}$ and the temperature in the smokehouse approximately $40^{\circ} \mathrm{C}$. The temperature of the cheeses, which was initially $4^{\circ} \mathrm{C}$, increased by approximately $4.6^{\circ} \mathrm{C}$.

The samples used for the study of PAH were those placed at the ends of the grilles $(1 \mathrm{~A}, 1 \mathrm{~B}, 4 \mathrm{~A}$, and $4 \mathrm{~B})$, as well as one cheese A and another B chosen among those placed in the middle. The number of experimental trials was 2 . Two samples were taken in each trial and these were analyzed in duplicate.

\section{Preparation of the Samples}

The samples for the study were prepared $10 \mathrm{~d}$ after they were smoked. Taking into account that the cheese region exhibiting a higher $\mathrm{PAH}$ contamination degree was the outer part (Guillén and Sopelana, 2004a), the portions studied were taken from this part, to a depth of approximately $1 \mathrm{~cm}$, and then chopped. The outer part of the cheeses accounted for a percentage relative to the whole cheese ranging from 49 to $62 \%$. Two aliquots of approximately $20 \mathrm{~g}$ were taken from each cheese after chopping the samples.

\section{Reagents and Materials}

The solvents employed for PAH analysis were cyclohexane and methanol, both HPLC grade (99.9+\%). Other reagents and materials used were potassium hydroxide, sodium chloride, anhydrous sodium sulfate, sodium tungstate dihydrate, and Supelclean LC-Si SPE (solid phase extraction; Supelco, Bellefonte, PA) tubes $3 \mathrm{~mL}(500 \mathrm{mg})$. All solvents, reagents, and materials mentioned are commercially available from SigmaAldrich (Steinheim, Germany), Panreac (Barcelona, Spain), and Supelco (Bellefonte, PA).

\section{PAH Standards}

The PAH standards used were the following: a commercial mixture of PAH standards dissolved in a mixture of dichloromethane:benzene (75:25), containing naphthalene, acenaphthylene, acenaphthene, fluorene, phenanthrene, anthracene, fluoranthene, pyrene, 
benzo $[c]$ phenanthrene, benz $[a]$ anthracene, chrysene, 7,12-dimethylbenz $[a]$ anthracene, benzo[ $b]$ fluoranthene, benzo $[j]$ fluoranthene, benzo $[k]$ fluoranthene, benzo $[a]$ pyrene, indeno[1,2,3-cd] pyrene, dibenz $[a, h]$ anthracene, benzo $[g h i]$ perylene, $\operatorname{dibenzo}[a, l]$ pyrene, $\operatorname{dibenzo}[a, i]$ pyrene, and dibenzo $[a, h]$ pyrene, in concentrations of approximately $500 \mu \mathrm{g} / \mathrm{mL}$; commercial individual cyclohexane solutions of 1,7-dimethylnaphthalene, 1,4-dimethylnaphthalene, 1,5-dimethylnaphthalene, 1-methylphenanthrene, 3,6-dimethylphenanthrene, 2,3-dimethylanthracene, 9,10-dimethylphenanthrene, 2-methylfluoranthene, 1-methylfluoranthene, $11 \mathrm{H}$ benzo[ $c]$ fluorene, 1-methylpyrene, 6-methylbenz $[a]$ anthracene, 7-methylbenz [ $a]$ anthracene, 1-methylchrysene, 2-methylchrysene, 3-methylchrysene, 4-methylchrysene, 5-methylchrysene, 6-methylchrysene, dibenz [a,j] anthracene, benzo $[b]$ chrysene, picene, anthanthrene, coronene, and dibenzo $[a, e]$ pyrene, in concentrations of approximately $10 \mu \mathrm{g} / \mathrm{mL}$; and a mixture of pure $\mathrm{PAH}$ dissolved in dichloromethane, containing 1-methylnaphthalene, 2-methylnaphthalene, 1,6-dimethylnaphthalene, 2,6-dimethylnaphthalene, 2,3-dimethylnaphthalene, $o$-terphenyl, 2-methylanthracene, 9-methylanthracene, $m$-terphenyl, $p$-terphenyl, 11H-benzo[a]fluorene, $11 \mathrm{H}$ benzo[b]fluorene, benzo[e]pyrene, and perylene, in concentrations ranging from 100 to $247.5 \mu \mathrm{g} / \mathrm{mL}$.

Naphthalene- $\mathrm{d}_{8}$, acenaphthene- $\mathrm{d}_{10}$, phenanthrene- $\mathrm{d}_{10}$, pyrene- $\mathrm{d}_{10}, \quad p$-terphenyl- $\mathrm{d}_{14}$, chrysene- $\mathrm{d}_{12}$, perylene- $\mathrm{d}_{12}$ and benzo $[$ ghi $]$ perylene- $\mathrm{d}_{12}$ were used as internal standards. The purity of these standards ranged from 97 to $99.5 \%$.

All the above-mentioned standards were used in the identification and quantification of the $\mathrm{PAH}$ present in the samples. All pure standards and solutions were obtained from Sigma-Aldrich, Supelco, and Symta (Madrid, Spain).

\section{Determination of PAH}

The methodology employed for the study of the samples was the same as described elsewhere (Guillén and Sopelana, 2004a). This basically includes the addition of a mixture of deuterated internal standards to the ground cheese, extraction of fat with cyclohexane in an ultrasonic bath, filtration, alkaline treatment of the fat with boiling methanolic potassium hydroxide for $4 \mathrm{~h}$ under reflux, extraction of PAH by shaking with cyclohexane in a separator funnel, washings of the extract, clarification with sodium tungstate, filtration, drying with anhydrous sodium sulfate, and purification with solid phase extraction tubes filled with silica. The final extract was studied by GC-MS in selected ion monitoring (SIM) mode. The chromatographic analysis of the samples was carried out by means of a Hewlett-Packard gas chromatograph model HP 6890 Series, equipped with a Mass Selective Detector 5973 and a Hewlett-Packard Vectra XM Series 4 computer (Palo Alto, CA). The column used was a fused-silica capillary column $(60-\mathrm{m}$ long $\times 0.25-\mathrm{mm}$ inner diameter $\times 0.25-\mu \mathrm{m}$ film thickness), coated with a nonpolar stationary phase (HP-5MS, 5\% phenyl methyl siloxane). The chromatographic conditions were the same as described elsewhere for the study of Palmero cheese (Guillén et al., 2007).

Identification of the compounds was based on their retention times and on the relative abundances of the ions selected for their identification. Quantification in SIM mode is based on the measurement of the peak area correspondent to the most abundant ion of each compound, and was carried out by means of the deuterated internal standards previously mentioned. Thus, naphthalene- $\mathrm{d}_{8}$ was used for quantification of naphthalene and its alkyl derivatives, acenaphthene- $\mathrm{d}_{10}$ for acenaphthylene and acenaphthene, phenanthrene- $\mathrm{d}_{10}$ for fluorene, phenanthrene, anthracene, and their alkyl derivatives, pyrene- $\mathrm{d}_{10}$ for fluoranthene and pyrene, $p$ terphenyl- $\mathrm{d}_{14}$ for $m$-terphenyl, $p$-terphenyl, benzofluorenes, and methyl-fluoranthenes/-pyrenes, chrysene$\mathrm{d}_{12}$ for benz $[a]$ anthracene and chrysene, perylene- $\mathrm{d}_{12}$ for benzofluoranthenes and benzopyrenes and, last, benzo $[$ ghi $]$ perylene- $\mathrm{d}_{12}$ for PAH with higher molecular weights.

\section{RESULTS AND DISCUSSION}

The results obtained reveal that the outer parts of the Herreño cheeses studied, both the smoked and the unsmoked one, contain PAH. The compounds detected, together with their concentrations, in $\mu \mathrm{g} / \mathrm{kg}$ of outer part, are shown in Table 1, in decreasing order of contamination. It can be observed in this table that light $\mathrm{PAH}$ (2 or 3 aromatic rings), above all naphthalene and its alkyl derivatives, but also acenaphthylene or phenanthrene, are the most abundant. It is worth noting the high proportion of alkylated $\mathrm{PAH}$, all of them derived from light PAH. The PAH profile of the cheeses studied will be analyzed in detail later in a separate section.

Among all of the PAH monitored in the study, 9-methylanthracene, 2,3-dimethylanthracene, 9,10-dimethylphenanthrene, 3,6-dimethylphenanthrene, benzo $[c]$ phenanthrene, $\quad 6$-methylbenz $[a]$ anthracene, 7-methylbenz $[a]$ anthracene, 1-methylchrysene, 2-methylchrysene, 3-methylchrysene, 4-methylchrysene, 5-methylchrysene, 6-methylchrysene, 7,12-dimethylbenz [a] anthracene, benzo[e]pyrene, perylene, dibenz $[a, j]$ anthracene, dibenz $[a, h]$ anthracene, benzo $[b]$ chrysene, picene, anthanthrene, coronene, dibenzo $[a, l]$ pyrene, dibenzo $[a, e]$ 
pyrene, dibenzo $[a, i]$ pyrene, and dibenzo $[a, h]$ pyrene were not detected in any of the samples studied.

\section{PAH Contamination Degree of the Smoked Cheeses Studied: Influence of the Position of the Cheeses in the Smokehouse}

Although all of the smoked Herreño cheeses studied were manufactured at the same time and smoked simultaneously in the same smokehouse, the total PAH concentrations of these cheeses are considerably different $(1,915.16 \mu \mathrm{g} / \mathrm{kg}$ in $1 \mathrm{~B}$ and $423.39 \mu \mathrm{g} / \mathrm{kg}$ in $4 \mathrm{~B})$. The unsmoked cheese has a considerably lower contamination degree $(33.65 \mu \mathrm{g} / \mathrm{kg})$.

According to the scheme of the positions of the cheeses in the smokehouse (Figure 1), the cheese 1B, which is the most contaminated one, was the nearest to the smoke entry and, what is more, it was kept in the smokehouse for almost double the time than cheeses A. Nevertheless, leaving aside cheeses $1 \mathrm{~B}$ and $1 \mathrm{~A}$, it can be observed that, despite their longer smoking time, the samples placed in the lower part (3B and 4B) show total $\mathrm{PAH}$ concentrations lower than the samples placed above (2A and $4 \mathrm{~A})$. It can also be noticed that, except for sample $1 \mathrm{~A}$, the cheeses closest to the smoke entry are the most contaminated. These differences could be due to the path followed by the smoke in the smokehouse, basically determined by the natural flow established between the entry and the exit. Thus, smoke tends to go up and, as it gets cold, PAH can condense, mainly on the surface of the cheeses placed in the main path of the smoke. In fact, the cheeses that could be considered as placed in such a path $(1 \mathrm{~B}, 2 \mathrm{~A}$, and $4 \mathrm{~A})$ are the most contaminated, whereas those placed further away from that path $(1 \mathrm{~A}, 3 \mathrm{~B}$, and $4 \mathrm{~B})$, show a lower contamination degree. Therefore, it could be concluded that the position of the cheeses within the smokehouse seems to have some influence on their PAH contamination degree. This influence seems more relevant than that of the duration of the process because, in general, the $\mathrm{PAH}$ content is higher in the cheeses placed in the main path of the smoked from the entry to the exit of the smokehouse. In this context, it seems evident that the entry of the smoke through different heights and sides of the smokehouse could provide a more homogeneous distribution of the smoke on the cheese surface and, consequently, a more homogeneous smoking degree of the cheeses. Furthermore, an extension of the distance between the smoke generation source and the smokehouse would probably avoid or at least reduce the deposit of these contaminants.

It is difficult to compare the PAH contamination degree of these Herreño cheeses with that of other smoked cheeses studied by different authors, because the num- ber of PAH determined here is far higher. In fact, most of the studies concerning PAH in food focus on a few $\mathrm{PAH}$, or even only on benzo[ $a]$ pyrene, the sole PAH classified as carcinogenic to humans (group 1) by the International Agency for Research on Cancer (IARC, 2010). However, it must not be forgotten that PAH appear in complex mixtures that include a large number of compounds, and that no evidence exists in relation to the carcinogenicity of many of them. Therefore, their potential presence should not be ignored.

If the total PAH concentrations of these smoked Herreño cheeses $(423.39-1,915.16 \mu \mathrm{g} / \mathrm{kg})$ are compared with those found previously in another type of Canary

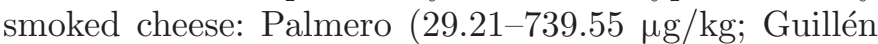
et al., 2007), and in other Spanish commercial smoked cheeses (36.31-1,037.23 $\mu \mathrm{g} / \mathrm{kg}$; Guillén and Sopelana, 2004a), it can be observed that the highest values generally correspond to Herreño cheeses. However, it must be pointed out, as will be discussed later, that the main contribution is due to the concentrations of the lightest $\mathrm{PAH}$, particularly naphthalene and its alkyl derivatives. By contrast, heavy PAH, among which most of the carcinogenic compounds are found, are very scarce.

The lower proportion of heavy PAH in comparison with those in Palmero cheese (Guillén et al., 2007) could be related to the smoking procedure used in each case: whereas Palmero cheese is smoked on a grill directly placed on a barrel where the smoke is produced, Herreño cheese is smoked in a smokehouse separated from the place where smoke is produced, resulting in a greater distance between the smoke source and the cheeses. This may affect the level of PAH deposits, especially of the heaviest ones, on the cheese surface.

\section{PAH Contamination Degree of the Unsmoked Cheese}

As can be seen in Table 1, the smoked Herreño cheeses and the unsmoked one differ considerably in the number of PAH and in their concentrations. As could be expected, the total PAH content of the unsmoked cheese is far lower $(33.65 \mu \mathrm{g} / \mathrm{kg})$.

At first, the occurrence of PAH in the unsmoked cheese could seem strange; however, other scientists have also found variable concentrations of some PAH, even of high molecular weight, in unsmoked cheese (Bosset et al., 1998; Pagliuca et al., 2003). Unlike that observed here, in the studies from the mentioned authors, benz $[a]$ anthracene was present in all of the unsmoked cheeses analyzed; in contrast, naphthalene, the most abundant compound in our samples, was not detected in any case.

The occurrence of PAH in the unsmoked cheese could be due to the presence of these compounds in the milk used to produce the cheese, concentrating in the fatty 
$\circlearrowleft \quad$ Table 1. Polycyclic aromatic hydrocarbons (PAH) detected in the outer part of the Herreño cheeses studied and their concentrations, expressed in $\mu \mathrm{g} / \mathrm{kg}$ (results are given as mean value $\pm \mathrm{SD})^{1}$

$1 \mathrm{~B}$

$2 \mathrm{~A}$

$4 \mathrm{~A}$

$1 \mathrm{~A}$

$3 \mathrm{~B}$

$4 \mathrm{~B}$

Unsmoked

Naphthalene $^{2}$

$401.17 \pm 2.12$

$217.73 \pm 21.40$

$171.91 \pm 52.98$

170.42

684.26

364.87

276.94

162.72

153.95

$170.42 \pm$

$15.97 \pm 12.68$

2-Methylnaphthalene

Dimethylnaphthalenes or isomers

$418.90 \pm 27.07$

681.15

$222.88 \pm 75.69$

$170.62+11.53$

$77.13 \pm 15.39$

372.54

$187.82 \pm 20.52$

$190.59 \pm 19.50$

7-Dimethylnaphthalene

1.6-Dimethylnaphthalene

1,4-+2,3-Dimethylnaphthalene

1,5-Dimethylnaphthalene

Dimethylnaphthalene or isomer

$79.15 \pm 0.16$

$105.50 \pm 52.49$

$102.51 \pm 64.07$

$106.32 \pm 5.23$

$85.59 \pm 3.53$

$96.59 \pm 21.59$

$76.24 \pm 2.40$

142.64

$73.66 \pm 2.21$
$53.38 \pm 1.65$

$31.59 \pm 1.94$

$64.63 \pm 47.14$

(9.38 \pm 1.65

$38.12 \pm 7.11$

$57.36 \pm 10.95$

$67.35 \pm 2.5$

6.11

119.9

$32.89 \pm 7.29$

$45.87 \pm 3.56$

$36.32 \pm 4.77$

$31.56 \pm 4.56$

$26.16+18.97$

$19.20 \pm 2.71$

$6.07 \pm 4.44$

$24.64 \pm 2.07$
$13.77 \pm 1.91$

$54.56 \pm 20.86$

$49.22 \pm 6.46$

Fluorene

Phenanthrene

Anthracene

Methyl-phenanthrenes/-anthracenes

$8.85 \pm 1.59$

$33.49 \pm 1.35$

$22.63 \pm 4.84$

$18.46 \pm 4.04$

$29.95 \pm 3.55$

$7.13 \pm 1.15$

17.3

-Methylphenanthrene

2-Methylphenanthrene

2-Methylanthracene

9-Methylphenanthrene 5

1-Methylphenanthrene

Dimethyl-phenanthrenes/-anthracenes

Dimethylphen. ${ }^{6}$ or isomer (1)

Dimethylphen. or isomer (2)

Dimethylphen. or isomer (3)

Dimethylphen. or isomer (4)

Dimethylphen. or isomer (5)

Dimethylphen. or isomer (6)

Fluoranthene

Pyrene

Methyl-fluoranthenes/-pyrenes

2-Methylfluoranthene

Methylflt. $^{7}$ or isomer (1)

Methylflt. or isomer (2)

Methylflt. or isomer (3)

Methylflt. or isomer (4)

1-Methylpyrene

$o$-Terphenyl

$m$-Terpheny

$p$-Terphenyl

1-Methylflt. +11H-benzo [a]fluorene

$5.85 \pm 1.34$

$19.23 \pm 8.98$

$4.25 \pm 1.52$
$10.61 \pm 3.83$

$23.14 \pm 8.25 \quad 15.28 \pm 5.39$

$3.77 \pm 1.38$

$3.49 \pm 0.47$

$4.78 \pm 0.38$

$2.54 \pm 0.29$

$2.91+0.46$

$3.58 \pm 0.17$

5.02

$0.54^{4}$
$0.38^{4}$

$1.26 \pm 0.13$

$1.16 \pm 0.11$

$1.68 \pm 0.08$

$3.14 \pm 0.28$

$2.85 \pm 0.33$

$2.48 \pm 0.33$

$0.31 \pm 0.08$

$0.33 \pm 0.01$

$0.35 \pm 0.00$

$0.52 \pm 0.00$

$13.07 \pm 1.71$
$3.85 \pm 1.80$

$3.85 \pm 1.80$

$1.79 \pm 0.79$

$2.20 \pm 0.89$

2.88

$0.47 \pm 0.04$

$0.47 \pm 0.04$

$0.50 \pm 0.05$

$0.45 \pm 0.05$

$0.26 \pm 0.01$

$0.92 \pm 0.21$

$0.16 \pm 0.03$

$11 \mathrm{H}$-Benzo $[c]$ fluoren

Benz $[a]$ anthracene

$0.19 \pm 0.07$

$0.44 \pm 0.17$

Chrysene $^{2}+$ triphenylene

Benzo[b]fluoranthene

Benzo $[j+k]$ fluoranthenes ${ }^{2}$

Benzo $[a]$ pyrene $^{2}$

Indeno $[1,2,3-c d]$ pyrene

Benzo $[$ ghi]perylene

$1.10 \pm 0.04$

$20.07 \pm 0.17$

$5.30+0.81$

$8.31 \pm 0.17$

$3.74 \pm 0.04 \pm 3.56$
16.04

$12.67 \pm 0.69$

$3.15 \pm 0.1$

6.51

$1.88 \pm 0.74$

$2.53 \pm 0.99$

$1.13 \pm 0.51$

$1.71 \pm 0.65$

$1.61 \pm 0.65$

1.18

$1.13 \pm 0.10$

$1.84 \pm 0.23$

$0.97 \pm 0.2$

$1.22 \pm 0.14$
$1.35 \pm 0.22$

0.49

$-\overline{1.11^{4}}$
$0.92^{4}$

$0.92^{4}$
$0.85^{4}$

$2.51 \pm 0.76$

$2.30 \pm 0.83$
1.06

1.0

$0.16 \pm 0.07$

$0.29 \pm 0.11$

$0.30 \pm 0.12$

$0.31 \pm 0.09$

$0.31 \pm 0.07$

$0.20 \pm 0.06$

$0.12 \pm 0.02$

$0.59 \pm 0.24$

$0.18 \pm 0.03$

$0.12 \pm 0.01$

$0.44 \pm 0.12$

$15.57 \pm 4.92$

$2.37 \pm 0.46$

$3.57 \pm 0.71$

$5.83 \pm 0.32$

$1.33 \pm 0.14$

5.07

$1.15 \pm 0.43$

$1.66 \pm 0.56$

$0.35 \pm 0.01$

$1.06 \pm 0.30$

$0.85 \pm 0.06$

1.29

$49.29 \pm 11.94$ 77.6

$3.78 \pm 0.72$

$23.34 \pm 6.68$

$2.33 \pm 0.53$

$2.46 \pm 0.28$

$19.86 \pm 4.51 \quad 1.71 \pm 0.53$

$20.58 \pm 0.50 \quad 1.78 \pm 0.58$

$10.21 \pm 2.44$

$20.65+2.30$

$3.15 \pm 0.27$

$10.48 \pm 2.67$

$7.59 \pm 2.57$

$2.75 \pm 0.65$

6.95

$1.26 \pm 0.29$

$0.96 \pm 0.46$

$1.41 \pm 0.51$

$1.38+0.45$

2.15

$$
\text { - }
$$

$0.25 \pm 0.07$

$0.19 \pm 0.04$

$0.23 \pm 0.05$

$1.03 \pm 0.28$

0.03

$0.46 \pm 0.12$

$0.62 \pm 0.19$

$0.39 \pm 0.09$

$0.39 \pm 0.08$

0.9

$0.54 \pm 0.15$

$0.36+0.13$

$0.39 \pm 0.09$

$1.18 \pm 0.51$

$1.71 \pm 0.64$

$1.62 \pm 0.58$

0.79

$0.08 \pm 0.01$

$0.22 \pm 0.02$

$0.25 \pm 0.00$

$0.80 \pm 0.10$

$0.20 \pm 0.08$

$0.10 \pm 0.04$

$0.35 \pm 0.09$

$0.14 \pm 0.03$

$0.08 \pm 0.01$

$0.39 \pm 0.13$

$0.57 \pm 0.20$

$0.14 \pm 0.05$

$0.09 \pm 0.03$
$0.21 \pm 0.02$

$0.21 \pm 0.02$
$0.04 \pm 0.01$

$0.05 \pm 0.0$

$0.49 \pm 0.08$

$1.55 \pm 0.05$

$1.15 \pm 0.06$

0.68

$0.06 \pm 0.00$

$0.06 \pm 0.01$

$0.10 \pm 0.00$

$0.16 \pm 0.04$

$0.14 \pm 0.04$

$0.16 \pm 0.02$

$2.75+1.29$

$0.17 \pm 0.01$

$0.05 \pm 0.02$

$0.25 \pm 0.03$

$0.07 \pm 0.01$

$0.09 \pm 0.01$

$0.17 \pm 0.05$

$0.32 \pm 0.06$

$0.59 \pm 0.04$

$0.46 \pm 0.02$

0.33

$0.06 \pm 0.00$

$0.11 \pm 0.01$

$0.02 \pm 0.01$

$0.04 \pm 0.00$

$0.04 \pm 0.02$

$0.50 \pm 0.11$

$0.19 \pm 0.03$

$0.11 \pm 0.09$

$0.03 \pm 0.00$

$0.04 \pm 0.00$

$0.06 \pm 0.00$

$0.15 \pm 0.00$

$0.78 \pm 0.23$

$0.58 \pm 0.20$

$0.79 \pm 0.27$

$1.20 \pm 0.21$

$1.03 \pm 0.11$

0.78

$0.03 \pm 0.01$

$0.07 \pm 0.02$

$0.10 \pm 0.03$ 
fraction of the cheese during its manufacturing process. In fact, the presence of PAH in milk has been revealed by the studies of several authors (Grova et al., 2000, 2002; Kishikawa et al., 2003), even though great differences exist between the results obtained. Thus, whereas Grova and coworkers $(2000,2002)$ did not find PAH with more than 4 aromatic rings in any of the milk samples studied and, in some cases, neither benz(a) anthracene nor chrysene, the studies of other authors have revealed the presence of the carcinogenic benzo(a) pyrene in milk of diverse origin (Kishikawa et al., 2003). The presence of PAH in the unsmoked cheese reveals the need to control the milk, to avoid the incorporation of these contaminants into cheese.

\section{PAH Profile of the Cheeses Studied}

As mentioned above, Table 1 shows that the most abundant compounds in the studied Herreño cheeses are the light PAH, among which naphthalene, acenaphthylene, or phenanthrene can be cited. This correlates well with the results of previous studies on the occurrence of PAH in other types of Spanish smoked cheeses (Guillén and Sopelana, 2004a; Guillén et al., 2007). Moreover, except for cheese $4 \mathrm{~A}$, no PAH with more than 4 aromatic rings has been detected in these cheeses. It can also be observed that, as in Palmero cheese (Guillén et al., 2007) and in other types of Spanish commercial smoked cheeses (Guillén and Sopelana, 2004a), the concentrations of light PAH are much higher than those of heavy $\mathrm{PAH}$, and that $\mathrm{PAH}$ concentrations tend to decrease as the molecular weight of the compounds increases.

Alkylated PAH are in high proportions, accounting for more than the $60 \%$ of the total PAH concentration in most of the samples, except in cheese $4 \mathrm{~B}$ and the unsmoked one, where these types of compounds are less abundant ( 48.2 and $44.2 \%$, respectively). The alkyl derivatives that most contribute to this sum are methyl- and dimethyl-naphthalenes, which represent almost $100 \%$ of the alkylated PAH. The individual concentrations of alkylated compounds are lower than those of their respective parent $\mathrm{PAH}$, the dimethyl derivatives being less abundant than the monomethyl derivatives. The concentration of 2-methylnaphthalene is slightly higher than that of naphthalene only in samples 1B and 2A (the most contaminated ones). All of these findings are in agreement with previous works on smoked cheese (Guillén and Sopelana, 2004a; Guillén et al., 2007).

In contrast to that observed for the individual concentrations of alkyl derivatives, it can be seen in Table 1 that, as in other types of Spanish smoked cheeses (Guillén and Sopelana, 2004a; Guillén et al., 2007), the total concentrations of mono- and di-methylnaphthalenes are, in general, higher or of the same order than those 
Table 2. Ratios between the concentrations of some polycyclic aromatic hydrocarbons (PAH) and their alkyl derivatives in the Herreño cheeses studied ${ }^{1}$

\begin{tabular}{lcccc}
\hline Item & Nap/MNap Nap/DMNap & Ph/MPh & Ph/DMPh \\
\hline Smoked cheese $^{2}$ & 0.6 & 0.6 & 1.7 & 6.0 \\
1B & 0.6 & 0.6 & 1.7 & 3.7 \\
$2 \mathrm{~A}$ & 0.6 & 0.6 & 1.7 & 12.9 \\
$4 \mathrm{~A}$ & 0.9 & 1.0 & 1.9 & 25.9 \\
1A & 1.0 & 1.0 & 1.2 & 4.5 \\
3B & 1.5 & 2.2 & 1.1 & 3.5 \\
4B & 41.1 & 62.0 & 20.7 & 93.5 \\
Variation coefficient & 2.6 & 2.7 & 0.6 & 1.1 \\
Unsmoked cheese & & & & \\
\hline
\end{tabular}

${ }^{1} \mathrm{Nap}=$ naphthalene; MNap = methylnaphthalenes; DMNap $=\operatorname{dim}$ ethylnaphthalenes; $\mathrm{Ph}=$ phenanthrene; $\mathrm{MPh}=$ methylphenanthrenes; $\mathrm{DMPh}=$ dimethylphenanthrenes

${ }^{2}$ Samples 1A, 2A, and 4A correspond to the cheeses placed on the upper shelf of the smokehouse and samples $1 \mathrm{~B}, 3 \mathrm{~B}$, and $4 \mathrm{~B}$ correspond to the cheeses placed on the lower shelf. The numbers refer to the position of the samples: 1 : the nearest to the smoke entry; 4 : the most distant from the smoke entry; 2 and 3 : intermediate positions.

of naphthalene, except in sample $4 \mathrm{~B}$ and the unsmoked cheese. However, in the case of phenanthrene/anthracene, the total of both mono- and di-methyl derivatives is lower than the concentration of phenanthrene in all of the samples except for the unsmoked cheese. Moreover, the sum of dimethyl derivatives is lower than that of monomethyl derivatives. The same can be observed for the total of methyl-fluoranthenes/-pyrenes in relation to the concentrations of their respective parent PAH. This also coincides with concentrations previously observed in other types of Spanish smoked cheeses (Guillén and Sopelana, 2004a; Guillén et al., 2007).

To make matters concerning alkylated PAH clearer, Table 2 shows the ratios between the concentrations of some PAH and their alkyl derivatives in the cheeses studied. It can be observed that, in the smoked cheeses, the first 3 ratios [naphthalene (Nap)/methylnaphtha- lene (MNap), Nap/dimethylnaphthalene (DMNap), and phenanthrene $(\mathbf{P h})$ /methylphenanthrene (MPh)] generally present very close values in most of the samples. The figures for ratios Nap/MNap and Nap/ DMNap are of the same order as those observed in smoked Palmero cheese (Guillén et al., 2007), whereas the ratio $\mathrm{Ph} / \mathrm{MPh}$ shows a little bit higher values in the Herreño cheese, which points to a lower proportion of methyl derivatives of $\mathrm{Ph} /$ anthracene $(\mathbf{A})$ in relation to their parent $\mathrm{PAH}$ in the latter. Moreover, as the concentration level of PAH decreases (higher in $1 \mathrm{~B}$ and lower in 4B), the values of the ratios Nap/MNap and Nap/DMNap increase, whereas those of the ratio $\mathrm{Ph} /$ $\mathrm{MPh}$, in general, decrease; this reveals a lower proportion of Nap alkyl derivatives, but a higher one of $\mathrm{Ph}$ derivatives in the samples with lower contamination degree. The ratio $\mathrm{Ph}$ /dimethylphenanthrene (DMPh), as observed in Palmero cheese (Guillén et al., 2007), is more variable, suggesting that $\mathrm{Ph}$ dimethyl derivatives could be more affected by variations in the smoking process than the rest of compounds included in these ratios. On the other hand, if the unsmoked cheese is compared with the smoked ones, it can be seen that the ratios Nap/MNap and Nap/DMNap are higher in the former, following the tendency that the lower the contamination, the higher the ratios Nap/MNap and Nap/DMNap; by contrast, those corresponding to $\mathrm{Ph}$ are lower, following the opposite tendency.

Studies performed previously (Guillén and Sopelana, 2004a; Guillén et al., 2007) have revealed the existence of relationships between the concentrations of certain pairs of PAH isomers. Table 3 shows the values of these ratios in the cheeses of this study. It can be observed that, despite the difference in the PAH contamination degree of the cheeses studied, a very constant ratio between the concentrations of some pairs of isomers is present. Specifically, the value of the ratio $\mathrm{Ph} / \mathrm{A}$,

Table 3. Ratios between the concentrations of certain polycyclic aromatic hydrocarbons (PAH) isomers in the Herreño cheeses studied ${ }^{1}$

\begin{tabular}{|c|c|c|c|c|c|c|}
\hline Item & $\mathrm{Ph} / \mathrm{A}$ & $\mathrm{Ft} / \mathrm{Py}$ & $\mathrm{Ch}+\mathrm{T} / \mathrm{BaA}$ & $\mathrm{BFt} / \mathrm{BPy}$ & BPer/IPy & 2MNap/1MNap \\
\hline \multicolumn{7}{|l|}{ Smoked cheese 2} \\
\hline $1 \mathrm{~B}$ & 4.2 & 1.1 & 2.5 & - & - & 1.6 \\
\hline $2 \mathrm{~A}$ & 4.1 & 1.1 & 1.5 & - & - & 1.6 \\
\hline $4 \mathrm{~A}$ & 4.1 & 1.1 & 1.5 & 1.4 & 0.8 & 1.6 \\
\hline $1 \mathrm{~A}$ & 4.0 & 1.3 & 1.9 & — & - & 0.9 \\
\hline $3 \mathrm{~B}$ & 4.4 & 1.3 & 2.1 & - & - & 1.7 \\
\hline $4 \mathrm{~B}$ & 2.8 & 1.2 & 1.8 & - & - & 1.4 \\
\hline Unsmoked cheese & 34.3 & 1.2 & - & - & - & 1.6 \\
\hline
\end{tabular}

${ }^{1} \mathrm{Ph}=$ phenanthrene; $\mathrm{A}=$ anthracene; $\mathrm{Ft}=$ fluoranthene; $\mathrm{Py}=$ pyrene; $\mathrm{Ch}=$ chrysene; $\mathrm{T}=$ triphenylene; $\mathrm{BaA}=$ benz $[a]$ anthracene; BFt $=$ benzofluoranthenes; $\mathrm{BPy}=$ benzopyrenes; $\mathrm{BPer}=$ benzo $[$ ghi $]$ perylene; IPy = indeno[1,2,3-cd] pyrene; $2 \mathrm{MNap}=2$-methylnaphthalene; $1 \mathrm{MNap}=1$-methylnaphthalene.

${ }^{2}$ Samples 1A, 2A, and 4A correspond to the cheeses placed on the upper shelf of the smokehouse and samples 1B, 3B, and $4 \mathrm{~B}$ correspond to the cheeses placed on the lower shelf. The numbers refer to the position of the samples: 1: the nearest to the smoke entry; 4: the most distant from the smoke entry; 2 and 3: intermediate positions. 
Table 4. Ratios between the concentrations of some pairs of polycyclic aromatic hydrocarbons $(\mathrm{PAH})$ that differ in one aromatic ring in the Herreño cheeses studied ${ }^{1}$

\begin{tabular}{lrrrl}
\hline Item & $\mathrm{Nap} / \mathrm{Al}$ & $\mathrm{Nap} / \mathrm{Ph}$ & $\mathrm{Ph} / \mathrm{Py}$ & $\mathrm{Py} / \mathrm{BaPy}$ \\
\hline Smoked cheese $^{2}$ & & & & \\
1B & 8.2 & 13.4 & 10.5 & - \\
2A & 6.5 & 9.5 & 10.1 & - \\
4A & 7.6 & 11.3 & 9.4 & 7.7 \\
1A & 7.3 & 11.6 & 11.0 & - \\
3B & 7.7 & 20.5 & 12.7 & - \\
4B & 8.3 & 22.5 & 7.4 & - \\
Variation coefficient & 8.6 & 36.5 & 17.3 & - \\
Unsmoked cheese & 63.9 & 15.5 & 4.1 & - \\
\hline
\end{tabular}

${ }^{1} \mathrm{Nap}=$ naphthalene; $\mathrm{Al}=$ acenaphthylene $\mathrm{Ph}=$ phenanthrene; $\mathrm{Py}=$ pyrene; $\mathrm{BaPy}=$ benzo $[a]$ pyrene.

${ }^{2}$ Samples 1A, 2A, and 4A correspond to the cheeses placed on the upper shelf of the smokehouse and samples $1 \mathrm{~B}, 3 \mathrm{~B}$, and $4 \mathrm{~B}$ correspond to the cheeses placed on the lower shelf. The numbers refer to the position of the samples: 1 : the nearest to the smoke entry; 4 : the most distant from the smoke entry; 2 and 3: intermediate positions.

which was found to vary depending on the PAH concentration level in smoked Palmero cheese (Guillén et al., 2007), is practically the same in all of the smoked cheeses (4.0-4.4), except for 4B (2.8). In the unsmoked cheese, this ratio (34.3) is far higher than in the smoked ones, which reveals a lower proportion of $\mathrm{A}$ in relation to $\mathrm{Ph}$ in the former. This could be considered as an indicator of the different origin of the contamination in the unsmoked cheese. In fact, values of the ratio $\mathrm{Ph} / \mathrm{A}$ higher than 10 have been considered characteristic of $\mathrm{PAH}$ mixtures with a petrogenic and not a pyrolytic origin (Ke et al., 2002).

Table 3 also shows that in the smoked cheeses the sum of chrysene $(\mathrm{Ch})$ and triphenylene $(\mathrm{T})$ is always higher than the benz $[a]$ anthracene concentration $(\mathrm{BaA})$, and that the values of the ratio $\mathrm{Ch}+\mathrm{T} / \mathrm{BaA}(1.5-2.5)$ are within the range observed in Palmero cheese (Guillén et al., 2007).

As noted in the study of Palmero cheese (Guillén et al., 2007), the ratio that remains most constant is that between the concentrations of fluoranthene and pyrene (Ft/Py; 1.1-1.3), also of the same order as in Palmero cheeses (Guillén et al., 2007). The value of this ratio is practically equal in all of the smoked cheeses (1.1-1.3) and in the unsmoked one (1.2). The same can be said about the ratio between the concentrations of the 2 monomethylnaphthalenes (2MNap/1MNap), which remains practically constant in most of the smoked cheeses (1.4-1.7), and the unsmoked one (1.6).

In relation to the ratios between the sums of benzofluoranthenes and benzopyrenes (BFt/BPy) on the one hand, and between the concentrations of benzo[ $g h i]$ perylene and indeno[ $1,2,3-c d]$ pyrene (BPer/IPy) on the other hand, it must be pointed out that these are also of the same order as in Palmero cheeses (Guillén et al.,
2007), in the one sample where these compounds were detected $(4 \mathrm{~A})$.

Previous works have also revealed the existence of a certain relationship between the concentrations of some pairs of PAH that differ in one aromatic ring, such as Py and benzo[a]pyrene (BaPy), in charbroiled hamburgers (Greenberg et al., 1993) or liquid smoke flavorings (Guillén et al., 2000a,b). In further studies on the occurrence of $\mathrm{PAH}$ in different types of smoked cheese (Guillén and Sopelana, 2004a; Guillén et al., 2007), additional ratios between other pairs of PAH were studied. It was observed from these studies that the values of some ratios varied depending on the PAH contamination degree and also on the vegetable matter used for smoking, whereas others, such as that between $\mathrm{Ph}$ and $\mathrm{Py}$ remained quite constant in all of the samples studied.

With the double objective of advancing the study of the usefulness of these types of ratios as well as of making a more thorough comparison of the PAH profile of the smoked Herreño cheese both with that of the unsmoked cheese and with other Spanish smoked cheeses, the ratios between the concentrations of some pairs of PAH were calculated. These are shown in Table 4. As expected, given that the 6 smoked cheeses were subjected to similar smoking conditions, the values of the ratios Nap/acenaphthylene (Al), Nap/Ph and $\mathrm{Ph} /$ Py are, in general, very similar in most of these smoked cheeses. The lower values of the ratio Nap/Al versus $\mathrm{Nap} / \mathrm{Ph}$ suggest a greater tendency to form $\mathrm{Al}$ than $\mathrm{Ph}$ from Nap in the smoke generation process employed in the smoking of Herreño cheeses; this contrasts with that observed in Palmero cheese (Guillén et al., 2007) and this difference could be due to the vegetable matter used for smoking. Together with $\mathrm{N} / \mathrm{Al}$, the ratio that exhibits fewer variations is $\mathrm{Ph} / \mathrm{Py}$. This agrees well with the results of previous works (Guillén and Sopelana, 2004a; Guillén et al., 2007) and also with those of Suchanová et al. (2008). These authors studied a large number of smoked cheese samples and found that although the ratio $\mathrm{Ph} / \mathrm{Py}$ stayed quite constant, the ratio $\mathrm{Py} / \mathrm{BaPy}$ differed from some samples to others depending on the smoking technology used. To be precise, the values for the ratio $\mathrm{Ph} / \mathrm{Py}$ in smoked Herreño cheese (7.4-12.7) are within the same range as those determined by Suchanová et al. (2008) in cheese samples smoked following different technologies (4-14). On the other hand, our only value for the ratio Py/ $\mathrm{BaPy}$ (7.7) is close to the values found by these authors in samples smoked with "liquid smoke" (6) and in those subjected to a household wood burning (14). According to the results of these authors, these types of smoking technologies led to the highest BaPy concentration in relation to Py. However, regarding this latter ratio (Py/ 
Table 5. Percentages of both total and heavy carcinogenic polycyclic aromatic hydrocarbons (PAH) in the Herreño cheeses studied

\begin{tabular}{lcc}
\hline & $\begin{array}{c}\text { Total } \\
\text { carcinogenic PAH } \\
(\%)\end{array}$ & $\begin{array}{c}\text { Heavy } \\
\text { carcinogenic } \text { PAH }^{1} \\
(\%)\end{array}$ \\
\hline Item & & \\
Smoked cheese $^{2}$ & 21.0 & 0.08 \\
1B & 20.4 & 0.10 \\
2A & 21.8 & 0.18 \\
4A & 28.2 & 0.09 \\
1A & 27.8 & 0.05 \\
3B & 40.4 & 0.11 \\
4B & 47.9 & 0.39 \\
Unsmoked cheese & &
\end{tabular}

${ }^{1}$ Without naphthalene.

${ }^{2}$ Samples $1 \mathrm{~A}, 2 \mathrm{~A}$, and $4 \mathrm{~A}$ correspond to the cheeses placed on the upper shelf of the smokehouse and samples $1 \mathrm{~B}, 3 \mathrm{~B}$, and $4 \mathrm{~B}$ correspond to the cheeses placed on the lower shelf. The numbers refer to the position of the samples: 1: the nearest to the smoke entry; 4 : the most distant from the smoke entry; 2 and 3: intermediate positions.

BaPy), we can draw hardly any conclusions because of the low number of cheese samples among those studied by our research group where BaPy was detected (Guillén and Sopelana, 2004a; Guillén et al., 2007).

In relation to the unsmoked cheese, the ratio Nap/ $\mathrm{Al}$ (63.9) is much higher than in the smoked cheeses, revealing a lower proportion of $\mathrm{Al}$ in relation to Nap in the former. By contrast, the value of the ratio $\mathrm{Ph} /$ Py (4.1) is lower in the unsmoked cheese, revealing a higher concentration of $\mathrm{Py}$ in relation to $\mathrm{Ph}$. These differences could again point to a different origin for the contamination in the unsmoked cheese.

In conclusion, it can be said that the PAH profile of the smoked Herreño cheese studied is very similar to that of other Spanish smoked cheeses. This leads us to think that the formation of PAH during smoke generation and their incorporation to cheese during the smoking process seems to have certain regularity, resulting in a very similar $\mathrm{PAH}$ profile, provided that smoke is not subjected to an additional treatment (for example, filtration) before coming into contact with the product.

The results of this work contribute to the concept that certain ratios between some pairs of PAH could be useful to provide information on the contamination source (Guillén et al., 2007).

\section{Carcinogenic PAH}

In relation to the presence of carcinogenic PAH, Nap and $\mathrm{Ch}$, considered as possibly carcinogenic to humans by the IARC (group 2B; IARC, 2002, 2010), are present in all the cheeses studied, both smoked and unsmoked. Benz $[a]$ anthracene, included by the IARC in group 2B too, has been detected in all of the smoked samples, but not in the unsmoked one. Other PAH also included in group $2 \mathrm{~B}$, such as benzo[b]fluoranthene, benzo[j] fluoranthene, benzo[ $k]$ fluoranthene, or indeno[1,2,3-cd] pyrene are present only in cheese $4 \mathrm{~A}$.

Table 5 shows the proportions, expressed in percentage relative to the total concentration of $\mathrm{PAH}$, of total carcinogenic PAH and heavy carcinogenic ones (without including Nap) in the cheeses studied. This table shows that although the percentage of carcinogenic $\mathrm{PAH}$ is about $21 \%$ in the 3 most contaminated cheeses $(1 \mathrm{~B}, 2 \mathrm{~A}$, and $4 \mathrm{~A}$ ), in the less contaminated ones this percentage is higher, above all in 4B. Moreover, the unsmoked cheese exhibits the greatest percentage of carcinogenic compounds (48\%). The explanation for this is the contribution of Nap, the most abundant compound in all of the studied cheeses, to the total of carcinogenic PAH. In fact, the percentage of heavy carcinogenic PAH in samples $1 \mathrm{~A}, 3 \mathrm{~B}$, and $4 \mathrm{~B}(0.05-0.11)$ is of the same order or even lower than in the rest of the smoked cheeses, where this value varies between 0.08 and $0.18 \%$. It must be pointed out that whereas the percentage of total carcinogenic PAH is within the range of those found in Palmero cheeses (11.2-48.3), the percentages of heavy carcinogenic ones is considerably lower in the Herreño cheeses.

Benzo $[a]$ pyrene was only detected in cheese $4 \mathrm{~A}$, in a concentration of $0.21 \mu \mathrm{g} / \mathrm{kg}$. This value is within the range of those found in other Spanish smoked cheeses, such as Palmero cheese (Guillén et al., 2007), other commercial ones (Guillén and Sopelana, 2004a), and in other types of smoked cheese, where concentrations varied between 0.03 and $3.8 \mu \mathrm{g} / \mathrm{kg}$ (Potthast, 1977; Lintas et al., 1979; Joe et al., 1984; De Martin et al., 1998; García Falcón et al., 1999; Michalski and Germuska, 2003; Pagliuca et al., 2003; Anastasio et al., 2004; Naccari et al., 2008; Suchanová et al., 2008). However, it must be pointed out that values vary greatly depending on the smoking process conditions and even on the part of the cheese studied, reaching concentrations of $7.8 \mu \mathrm{g} / \mathrm{kg}$ in some cheeses (Michalski and Germuska, 2003). In contrast, there are also studies where BaPy has not been detected in any of the samples studied (Riha et al., 1992).

The BaPy concentration in the outer part of cheese $4 \mathrm{~A}$ is far lower than the maximum limit of $10 \mu \mathrm{g} / \mathrm{kg}$ allowed in Spain in the rind of ripened smoked cheeses (Real Decreto 1113/2006, de 29 de septiembre; Ministerio de la Presidencia, 2006). Nevertheless, considering that $\mathrm{BaPy}$ is mainly concentrated in the outer part (Guillén and Sopelana, 2004a) and that the outer part accounted for $49.36 \%$ of the whole cheese in sample $4 \mathrm{~A}$, the concentration corresponding to the whole sample would be $0.10 \mu \mathrm{g} / \mathrm{kg}$. This value is considerably lower than the maximum of $5 \mu \mathrm{g} / \mathrm{kg}$ established for other types of smoked foods (Commission Regulation No 
208/2005; European Commission, 2005b), although higher than that allowed in foods smoked with smoke flavorings (Council Directive 88/388/EEC; EEC, 1988). However, in Spain, none of the limits mentioned affect smoked cheese.

As mentioned above, BaPy has only been detected in one of the samples studied. In contrast, other PAH considered possibly carcinogenic to humans by the IARC (group 2B), such as benz [a] anthracene or Ch, are present in all of them, and the same has been observed in previous works (Guillén and Sopelana, 2004a; Guillén et al., 2007). These findings contribute to the idea that benzo $[a]$ pyrene alone does not seem to be a suitable indicator for the occurrence and toxicity of genotoxic and carcinogenic PAH.

Although heavy PAH, especially those with 5 or more aromatic rings, are the most studied because of their mutagenicity, genotoxicity, or carcinogenicity in experimental animals, the potential contribution of light $\mathrm{PAH}$ to the genotoxic or carcinogenic effects of PAH-contaminated food should not be ignored, because these latter are the most abundant in all of the food samples studied by our research group, both smoked (Guillén and Sopelana, 2004a; Guillén et al., 2007) and unsmoked (Guillén and Sopelana, 2004b; Guillén et al., 2004). In this context, Nap deserves special attention, because it accounts for a percentage of the total PAH concentration ranging from 20 to $47 \%$ in the samples of this study; moreover, as mentioned above, it has been included in group 2B of the IARC (IARC, 2002) and the National Toxicology Program (NTP) has recently evaluated this $\mathrm{PAH}$ and classified it as reasonably anticipated to be a human carcinogen (NTP, 2004). Alkylated derivatives, which account for a high proportion of the total PAH concentration, should not be ignored either due to their wide distribution, because methyl substitution in some compounds could result in hydrocarbons of very great carcinogenic potency (Guillén and Sopelana, 2003).

On the other hand, some PAH, despite their inability to produce tumors per se, contribute to an increase in the incidence of some types of tumors produced by complete carcinogens such as $\mathrm{BaPy}$ when administered together with them; fluoranthene and Py can be cited as examples (Guillén and Sopelana, 2003).

In conclusion, it can be said that the traditional smoking process applied to the Herreño cheese studied here results in a very low content of heavy carcinogenic PAH. However, it would be desirable to optimize this process to decrease the concentrations of light and alkylated PAH, whose effects on human health have not been definitively established yet. Moreover, the study of the PAH profile of the cheese reveals that some ratios between the concentrations of certain pairs of $\mathrm{PAH}$, such as $\mathrm{Ft} / \mathrm{Py}$ or $\mathrm{Ph} / \mathrm{Py}$, remain practically constant, independent of the smoking process and of the PAH contamination level; in contrast, other ratios, such as Nap/MNap, Nap/DMNap or $\mathrm{Ph} / \mathrm{MPh}$, seem to be influenced by the PAH concentration level. Finally, some ratios, such as $\mathrm{Ph} / \mathrm{A}$ or $\mathrm{Nap} / \mathrm{Al}$, can help us to distinguish between $\mathrm{PAH}$ contamination coming from smoking or from other sources.

Thus, although the occurrence of PAH in food commodities has been studied for many decades, the presence of this type of contaminants still constitutes a cause for concern, because very few exhaustive studies exist on the whole PAH profile and, consequently, a lack of data about the presence of these contaminants in food. This information is necessary to evaluate the possible risk derived from the consumption of foods and, in fact, SCF stressed that data collection on the whole PAH profile should continue to be able to evaluate the contamination of food commodities and any future change in the PAH profile. Moreover, further toxicological studies should be carried out to know the risk derived from the ingestion of the most abundant $\mathrm{PAH}$ in food. Meanwhile, PAH contamination of food should be kept to the minimum possible. In this context, the findings of this work show that the position of the cheeses in the smokehouse can have an influence on their PAH contamination degree. Therefore, improving the design of smokehouses might contribute to decreasing the PAH contamination of smoked cheese.

\section{ACKNOWLEDGMENTS}

This work has been supported by the Ministerio de Ciencia y Tecnología (CAL02-075-C3-2, AGL200909904) and the Gobierno del País Vasco (GIC10/IT463-10). G. Palencia thanks the Universidad del País Vasco (Vitoria, Spain) for a predoctoral fellowship.

\section{REFERENCES}

Anastasio, A., R. Mercogliano, L. Vollano, T. Pepe, and M. L. Cortesi. 2004. Levels of benzo $[a]$ pyrene (BaP) in "Mozzarella di Bufala Campana" cheese smoked according to different procedures. J. Agric. Food Chem. 52:4452-4455.

Baumard, P., H. Budzinski, P. Garrigues, H. Dizer, and P. D. Hansen. 1999. Polycyclic aromatic hydrocarbons in recent sediments and mussels (Mytilus edulis) from the Western Baltic Sea: Occurrence, bioavailability and seasonal variations. Mar. Environ. Res. $47: 17-47$.

Bosset, J. O., U. Bütikofer, O. Dafflon, H. Koch, L. Scheurer-Simonet, and R. Sieber. 1998. Teneur en hydrocarbures aromatiques polycycliques de fromages avec et sans flaveur de fumée. Sci. Aliments 18:347-359.

De Martin, S., P. Matcovich, D. Nanut, S. Zulian, and V. Siardi. 1998. Determination of polycyclic aromatic hydrocarbons $(\mathrm{PAH})$ in smoked foods. Boll. Chim. Igien. Parte Sci. 49:177-181.

EEC (European Economic Community). 1988. Council Directive $88 / 388 /$ EEC of 22 of June of 1988 on the approximation of the laws of the Member States relating to flavorings for use in food- 
stuffs and to source materials for their production. Off. J. Eur. Union L 184, 15.07.1988:61-66.

European Commission. 2005a.Commission Recommendation 2005/108/ EC of 4 February 2005 on the further investigation into the levels of polycyclic aromatic hydrocarbons in certain foods. Off. J. Eur. Union L34, 8.02.2005:43-45.

European Commission. 2005b. Commission Regulation (EC) No 208/2005 of 4 February 2005 amending Regulation (EC) No $466 / 2001$ as regards polycyclic aromatic hydrocarbons. Off. J. Eur. Union L 34, 8.02.2005:3-5.

Fresno, M., S. Alvarez, N. Darmanin, P. Méndez, E. Fernández, and M. D. Guillén. 2004. La industria quesera en la isla de El Hierro: Pasado, presente y futuro. Alimentación, Equipos y Tecnología 192:69-73.

García Falcón, M. S., S. González Amigo, M. A. Lage Yusty, and J. Simal Lozano. 1999. Determination of benzo[a]pyrene in some Spanish commercial smoked products by HPLC-FL. Food Addit. Contam. 16:9-14.

Greenberg, A., C.-H. Hsu, N. Rothman, and P. T. Strickland. 1993. PAH profiles of charbroiled hamburgers: Pyrene $/ \mathrm{b}[a] \mathrm{p}$ ratios and presence of reactive PAH. Polycycl. Aromat. Compd. 3:101-110.

Grova, N., C. Feidt, C. Crépineau, C. Laurent, P. E. Lafargue, A Hachimi, and G. Rychen. 2002. Detection of polycyclic aromatic hydrocarbon levels in milk collected near potential contamination sources. J. Agric. Food Chem. 50:4640-4642.

Grova, N., C. Laurent, C. Feidt, G. Rychen, F. Laurent, and E. Lichtfouse. 2000. Gas chromatography-mass spectrometry study of polycyclic aromatic hydrocarbons in grass and milk from urban and rural farms. Eur. J. Mass Spectrom. (Chichester, Eng.) $6: 457-460$

Guillén, M. D., G. Palencia, P. Sopelana, and M. L. Ibargoitia. 2007. Occurrence of polycyclic aromatic hydrocarbons in artisanal Palmero cheese smoked with two types of vegetable matter. J. Dairy Sci. 90:2717-2725

Guillén, M. D., and P. Sopelana. 2003. Polycyclic aromatic hydrocarbons in diverse foods. Pages 175-198 in Food Safety: Contaminants and Toxins. J. P. F. D'Mello, ed. CABI Publishing, Wallingford, UK.

Guillén, M. D., and P. Sopelana. 2004a. Occurrence of polycyclic aromatic hydrocarbons in smoked cheese. J. Dairy Sci. 87:556-564.

Guillén, M. D., and P. Sopelana. 2004b. Load of polycyclic aromatic hydrocarbons in edible vegetable oils: Importance of alkylated derivatives. J. Food Prot. 67:1904-1913.

Guillén, M. D., P. Sopelana, and G. Palencia. 2004. Polycyclic aromatic hydrocarbons and olive pomace oil. J. Agric. Food Chem. 52:2123-2132.

Guillén, M. D., P. Sopelana, and M. A. Partearroyo. 2000a. Determination of polycyclic aromatic hydrocarbons in commercial liquid smoke flavorings of different composition by gas chromatographymass spectrometry. J. Agric. Food Chem. 48:126-131.

Guillén, M. D., P. Sopelana, and M. A. Partearroyo. 2000b. Polycyclic aromatic hydrocarbons in liquid smoke flavorings obtained from different types of wood. Effect of storage in polyethylene flasks on their concentrations. J. Agric. Food Chem. 48:5083-5087.

IARC (International Agency for Research on Cancer). 2002. Some traditional herbal medicines, some mycotoxins, naphthalene and styrene. In IARC Monographs on the evaluation of the carcinogenic risk of chemicals to humans. Vol. 82. IARC, Lyon, France.
IARC (International Agency for Research on Cancer). 2010. Some non-heterocyclic polycyclic aromatic hydrocarbons and some related exposures. In IARC Monographs on the evaluation of the carcinogenic risk of chemicals to humans. Vol. 92. IARC, Lyon, France.

Joe, F. L. Jr., J. Salemme, and T. Fazio. 1984. Liquid chromatographic determination of trace residues of polynuclear aromatic hydrocarbons in smoked foods. J. Assoc. Off. Anal. Chem. 67:1076-1082.

Ke, L., T. W. Y. Wong, Y. S. Wong, and N. F. Y. Tam. 2002. Fate of polycyclic aromatic hydrocarbon $(\mathrm{PAH})$ contamination in a mangrove swamp in Hong Kong following an oil spill. Mar. Pollut. Bull. 45:339-347.

Kishikawa, N., M. Wada, N. Kuroda, S. Akiyama, and K. Nakashima. 2003. Determination of polycyclic aromatic hydrocarbons in milk samples by high-performance liquid chromatography with fluorescence detection. J. Chromatogr. B. Analyt. Technol. Biomed. Life Sci. 789:257-264.

Lintas, C., M. C. De Matthaeis, and F. Merli. 1979. Determination of benzo $[a]$ pyrene in smoked, cooked and toasted food products. Food Cosmet. Toxicol. 17:325-328.

Maga, J. A. 1988. Smoke in Food Processing. CRC Press, Boca Raton, FL.

Michalski, R., and R. Germuska. 2003. The content of benzo $[a]$ pyrene in Slovakian smoked cheese. Pol. J. Food Nutr. Sci. 12:33-37.

Naccari, C., M. Cristani, P. Licata, F. Giofre, and D. Trombetta. 2008. Levels of benzo $[a]$ pyrene and benzo $[a]$ anthracene in smoked "Provola" cheese from Calabria (Italy). Food Addit. Contam. Part B 1:78-84.

NTP (National Toxicology Program). 2004. Eleventh Report on Carcinogens. U.S. Department of Health and Human Services, Public Health Service, Washington, DC.

Pagliuca, G., T. Gazzotti, E. Zironi, G. P. Serrazanetti, D. Mollica, and R. Rosmini. 2003. Determination of high molecular mass polycyclic aromatic hydrocarbons in a typical Italian smoked cheese by HPLC-FL. J. Agric. Food Chem. 51:5111-5115.

Potthast, K. 1977. Polycyclic aromatic hydrocarbons in smoked meat products. An application of a new method. Acta Aliment. Pol. 3:195-201.

Ministerio de la Presidencia. 2006. Real Decreto 1113/2006, de 29 de septiembre, por el que se aprueban las normas de calidad para quesos y quesos fundidos. B.O.E. 239, 6.10.2006:34717-34720.

Riha, W. E., W. L. Wendorff, and S. Rank. 1992. Benzo[a]pyrene content of smoked and smoked-flavored cheese products sold in Wisconsin. J. Food Prot. 55:636-638.

Rodríguez-Garcia, M. E. C. de Lira, E. Hernández-Becerra, M. A. Cornejo-Villegas, A. J. Palacios-Fonseca, I. Rojas-Molina, R. Reynoso, L. C. Quintero, A. Del-Real, T. A. Zepeda, and C. Muñoz-Torres. 2007. Physicochemical characterization of nopal pads (Opuntia ficus indica) and dry vacuum nopal powders as a function of the maturation. Plant Foods Hum. Nutr. 62:107-112.

SCF (Scientific Committee on Food). 2002. European Commission. Opinion of the Scientific Committee on Food on the risks to human health of polycyclic aromatic hydrocarbons in food. Report SCF/CS/CNTM/PAH/29 Final (December 4, 2002), Brussels, Belgium

Suchanová, M., J. Hajšlová, M. Tomaniová, V. Kocourek, and L. Babička. 2008. Polycyclic aromatic hydrocarbons in smoked cheese. J. Sci. Food Agric. 88:1307-1317. 